\title{
THE CYTOCHEMICAL LOCALIZATION OF ADENYLATE CYCLASE ACTIVITY IN MUCOUS AND SEROUS CELLS OF THE SALIVARY GLAND
}

\author{
Sun-Kee Kim \\ Veterans Administration Hospital and Department of Anatomy, The University of \\ Michigan Medical School, Ann Arbor, Michigan 48105
}

The present study was undertaken to localize adenylate cyclase activity in salivary glands by cytochemical means. For the study, serous parotid glands and mixed sublingual glands of the rat were used. Pieces of the fixed glands were incubated with adenosine triphosphate (ATP) or adenylyl-imidodiphosphate (AMP-PNP) as substrate: inorganic pyrophosphate or PNP liberated upon the action of adenylate cyclase on the substrates is precipitated by lead ions at their sites of production.

In both glands, the reaction product was detected along the myoepithelial cell membranes in contact with secretory cells, indicating that a high level of adenylate cyclase activity occurs in association with these cell membranes. The association with a high level of the enzyme activity might be related to the contractile nature of myoepithelial cells which are supposed to aid secretory cells in discharging secretion products.

A high level of adenylate cyclase activity was also detected associated with serous secretory cells (acinar cells of the parotid gland and demilune cells of the sublingual gland), but not with mucous secretory cells. In serous cells, deposits of reaction product were localized along the extracellular space of the apical cell membrane bordering the lumen. This is the portion of the cell membrane which fuses with the granule membranes during secretion. Since the granule membranes are not associated with a detectable level of adenylate cyclase activity, it appears that the enzyme activity becomes activated or associated with the granule membranes as they become part of the cell membrane by fusion. The association with a high level of adenylate cyclase activity appears to be related to the ability of the membrane to fuse with other membranes. It is likely, since the luminal membrane of mucous cells which does not fuse with mucous granule membranes during secretion is not associated with a detectable enzyme activity.

\section{INTRODUCTION}

Adenosine 3', 5'-monophosphate (cyclic AMP) has been established as an intermediate in the action of various hormones and other biologically active agents $(1-3)$. The secretion of salivary glands also appears to be mediated by cyclic AMP as demonstrated in the rat parotid gland (4-6), and it has been suggested that an important 
function of cyclic AMP is the regulation of cellular secretory activity (7). The formation of cyclic AMP from adenosine triphosphate (ATP) is catalyzed by adenylate cyclase (8), which appears to be localized in cell membranes (9). Thus, it is likely that adenylate cyclase, or factors controlling this enzyme activity, have a significant role in the regulation of cellular secretory function (10).

This is especially likely in the case of serous secretroy cells in which the cell membrane takes a direct participation in the process of secretion $(11-13)$. The granule discharge in serous cells occurs by the fusion of the secretory granule membranes with the cell membrane at the lumen. The luminal membrane becomes greatly extended during secretion as a consequence of this fusion, and the extended membrane is removed subsequently by the cell following the completion of secretion. Previous biochemical studies of the rat parotid gland have indicated that adenylate cyclase activity is largely associated with the cell membrane fractions (10). However, the precise localization of the enzyme activity in the gland remains uncertain, and it is unknown whether or not the localization of the enzyme activity is affected during secretion in relation to the changes in the membrane distribution.

Previous studies (14-18) have indicated that the secretory mechanisms of mucous cells are different from those of serous cells: in mucous cells, secretory granules discharge through gaps formed in the apical cell membrane without involving the fusion of the granule and cell membranes. Thus, it would be of great interest to find out if the membranes of mucous secretory cells are also associated with adenylate cyclase activity, and if so, whether or not there are differences in the distribution of the enzyme activity in these cells as compared to that in serous cells.

Recently, it has been shown that the localization of adenylate cyclase activity can be demonstrated cytochemically at the electron microscope level in the liver (19), and in the islets of Langerhans of the pancreas (20). The basis of this cytochemical technique is the precipitation of the inorganic pyrophosphate produced by adenylate cyclase action on ATP by heavy metal salts (lead ions) and visualizing the complex in the electron microscope (19). Furthermore, it has been shown that the specificity of the method can be increased by using adenylyl-imidodiphosphate (AMP-PNP) as substrate instead of ATP (20), as AMP-PNP has been shown to be an effective substrate for adenylate cyclase (21) but not for ATPase and other phosphohydrolases (22). The present study aims to localize adenylate cyclase activity in salivary glands by cytochemical means, and to compare the localization of the enzyme activity in serous and mucous secretory cells.

\section{METHODS}

Parotid and sublingual glands of the rat were used for the study. The glands were fixed by perfusing the rat through the heart with $1 \%$ glutaraldehyde containing $4.5 \%$ glucose buffered to $\mathrm{pH} 7.4$ with $0.05 \mathrm{M}$ sodium cacodylate. The glands were removed, sliced into smaller pieces, and further fixed in the same fixative for about $30 \mathrm{~min}$. The fixed tissues were rinsed several times in $0.05 \mathrm{M}$ cacodylate buffer containing $8 \%$ glucose and stored overnight in the refrigerator. The tissues were further sliced into smaller pieces by using either scalpel blades or a Smith-Fa rquhar tissue sectioner prior to incubation. 
The composition of the incubation medium and the procedures used in this study are basically similar to those described by Reik et al. (19), and Howel and Whitfield (20). The incubation medium consisted of $80 \mathrm{mM}$ Tris-maleate buffer, $2 \mathrm{mM}$ magnesium sulfate, $2 \mathrm{mM}$ theophylline, and $4 \mathrm{mM}$ lead nitrate. Either $0.5 \mathrm{mM}$ ATP or $0.5 \mathrm{mM}$ AMP-PNP (obtained from ICN, Ltd., Irvine, Calif.) was used as substrate. Sodium fluoride (10 mM) or isoproterenol was added as activator. The incubation medium was adjusted to $\mathrm{pH} 7.5$ with ATP as substrate. With AMP.PNP as substrate, however, some tissues were incubated at $\mathrm{pH} 8.5$, as sodium fluoride-stimulated adenyl cyclase seems to exhibit a $\mathrm{pH}$ optimum at $8.5-8.8(23)$.

As controls, some tissues were incubated in the complete medium either without the substrate or without the activator. To determine whether or not the amount of reaction product observed is related to the amount of activator added, incubations were carried out with varying concentrations $\left(10^{-5}, 10^{-4}, 10^{-3}, 10^{-2} \mathrm{M}\right)$ of isoproterenol.

The tissues were incubated for $30 \mathrm{~min}$ at $30^{\circ} \mathrm{C}$ with ATP as substrate. However, the incubation time was extended to $1 \mathrm{hr}$ in the case of AMP-PNP as a stronger reaction was obtained following the incubation for longer periods of time. At the end of the incubations, the tissues were rinsed briefly in Tris-maleate buffer and then in cacodylate buffer before fixing with $1 \% \mathrm{OSO}_{4}$ solution for $1 \mathrm{hr}$. The incubated tissues were processed for electron microscopy, and sections prepared on a Porter-Blum MT2-B microtome were studied with a Hitachi $1 \mathrm{lc}$ electron microscope after staining with uranyl acetate or uranyl acetate followed by lead citrate.

\section{RESULTS}

\section{The Morphology of the Glands}

Two types of glands, sublingual and parotid glands of the rat, have been used in this study. The sublingual gland is a mixed gland which consists of mucous acinar cells and serous demilune cells (Fig. 1). The mucous cells predominate in the gland and form secretory tubules. The mucous granules of these cells are often found fused and appear less electron dense than the serous granules of the demilune cells. The demilune cells, located at the blunt end of the secretory tubules, contain granules which resemble those in cells of other serous glands, such as parotid glands and pancreas.

The parotid gland, on the other hand, is made up of only one type of secretory cells which forms acini and contains serous granules. The morphological appearances of the parotid acinar cells are very similar to those of the demilune cells of the sublingual gland shown in Fig. 1; the acinar cells of parotid glands contain many electron-dense, zymogen-like granules and a large amount of endoplasmic reticulum, as do the demilune cells of the sublingual gland.

In both sublingual and parotid glands, myoepithelial cells are present and are localized at the base of the secretory cells in contact with the membranes of the latter cells (Figs. 1 and 3). Fragments of myoepithelial cell cytoplasm are frequently seen but cell bodies containing nuclei are only occasionally observed, indicating that these cells have branching processes. The cytoplasm of myoepithelial cells (Fig. 3) is similar in appearance to that of smooth muscle cells in containing myofibrils and small pinocytic vesicles. The contractility of myoepithelial cells is supposed to aid the secretory cells in secretion. 


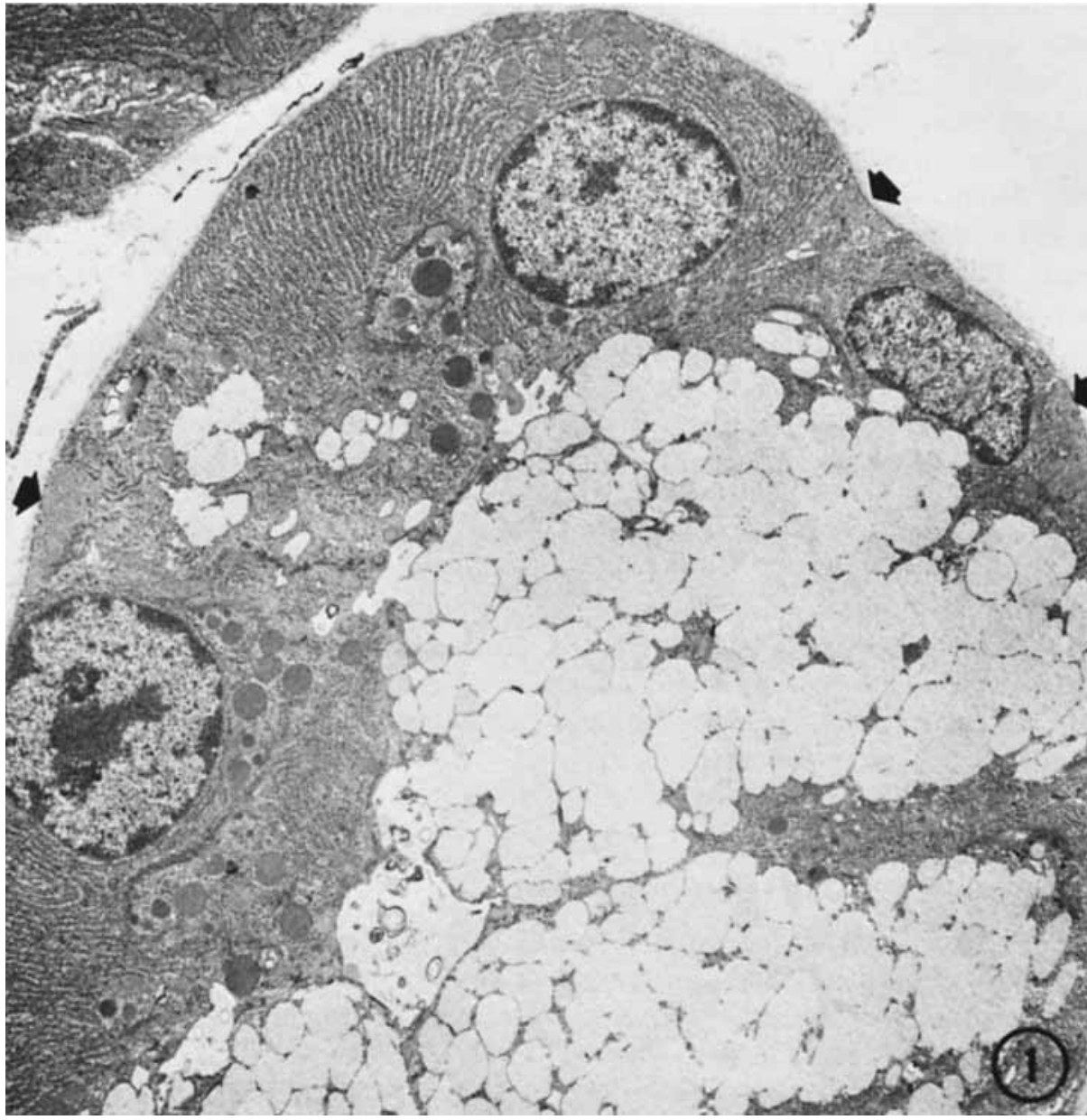

Fig. 1. A terminal portion of an acinus of the rat sublingual gland showing mucous acinar cells and serous demilune cells. The demilune cells contain a large number of parallel arrays of endoplasmic reticulum and dense, zymogen-like granules. The processes of myoepithelial cells (arrows) are seen at the base of the acinus in contact with both mucous and serous cells. $(\times 4,950)$.

As was mentioned earlier, serous cells, such as the acinar cells of the parotid gland and demilune cells of the sublingual gland in this study, discharge their secretory granules by exocytosis; the content of the granules is discharged into the lumen by fusion of the granule membrane with the cell membrane. Thus, the gland stimulated to secrete, as shown in Fig. 2, reveals extended membranes around the widened lumen resulting from the addition of granule membranes to the luminal membrane during secretion.

\section{The Cytochemistry of the Glands}

Deposits of the reaction product have been detected in two sites involving cell membranes in the glands incubated with AMP-PNP as substrate, indicating a high level of 


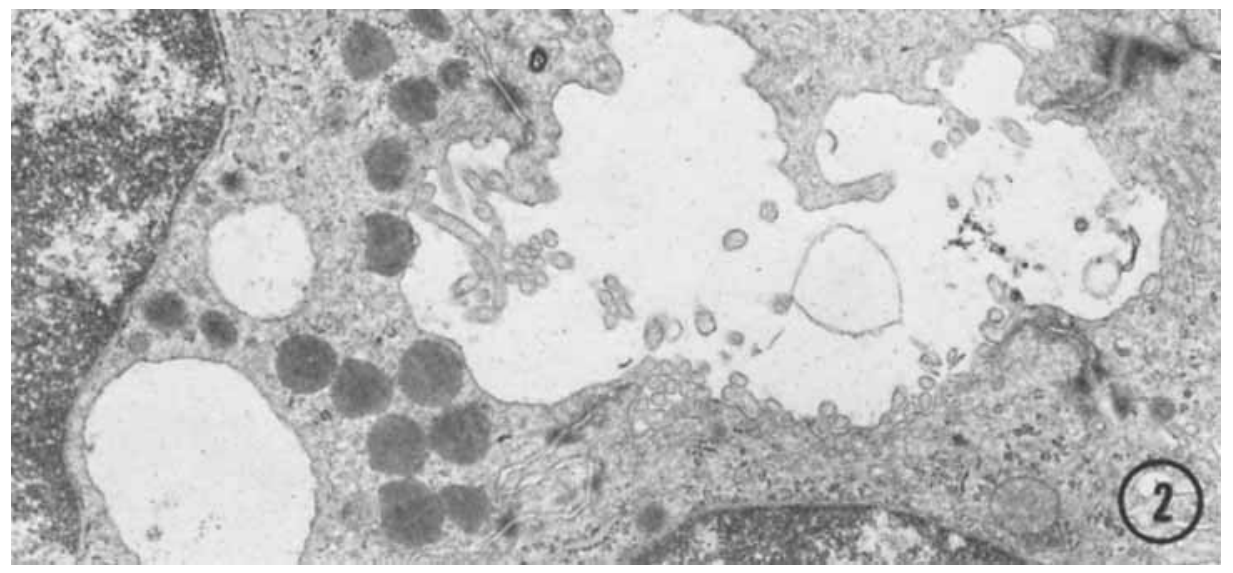

Fig. 2. A portion of the parotid gland of a rat stimulated to secrete by injection of isoproterenol $(0.8 \mathrm{mg} / 100 \mathrm{gm}$ body weight) and sacrificed $30 \mathrm{~min}$ after the injection. The granules of serous cells discharge by exocytosis; the granule membranes fuse with the cell membrane at the lumen. Thus, the extended membrane around the enlarged lumen is obvious. $(x 5,400)$.

adenylate cyclase activity associated with these two membranes. One such site of positive reaction product is the myoepithelial cell membrane in contact with both mucous and serous secretory cells. As can be seen in Fig. 4, the reaction product is also detected in small vesicles along the cell membrane of the myoepithelial cell facing the secretory cells. However, the reaction product is detected neither in association with the membrane at the basal side of the myoepithelial cell nor in vesicles along this membrane. The localization of the reaction product is the same in myoepithelial cells associated with serous and mucous secretory cells.

The other site of the deposits of reaction product is the luminal membrane of serous secretory cells. The same membrane of mucous cells, however, does not reveal the reaction product. This is illustrated in micrographs of incubated sublingual glands (Figs. 5,6) and of parotid glands (Figs. 7, 8). As can be seen in incubated sublingual glands shown in Fig. 5, the reaction product is clearly confined to the luminal surface of the demilune cell. No deposit is noted along the luminal surface of mucous cells shown in the same field. The reaction product is localized in the extracellular surface along the cell membrane bordering the luminal surfaces (Fig. 6).

The localization of the reaction product in cells of the parotid gland is similar to that seen in demilune cells of the sublingual gland. As shown in Fig. 7, the reaction product is localized along the luminal surface of the apical cell membrane of the acinar cell. The reaction product is not detected in association with any other membranes including the secretory granule membrane.

However, the observations of the parotid glands which were stimulated to secrete prior to the incubation have indicated that the membranes of the secretory granules become associated with the reaction product following the fusion with the cell membrane. This can be seen in Fig. 8 which shows a portion of stimulated parotid gland. The cells are depleted of secretory granules and the enlargement of the luminal space is obvious. Deposits of the reaction product occur along the luminal surface of the ex- 


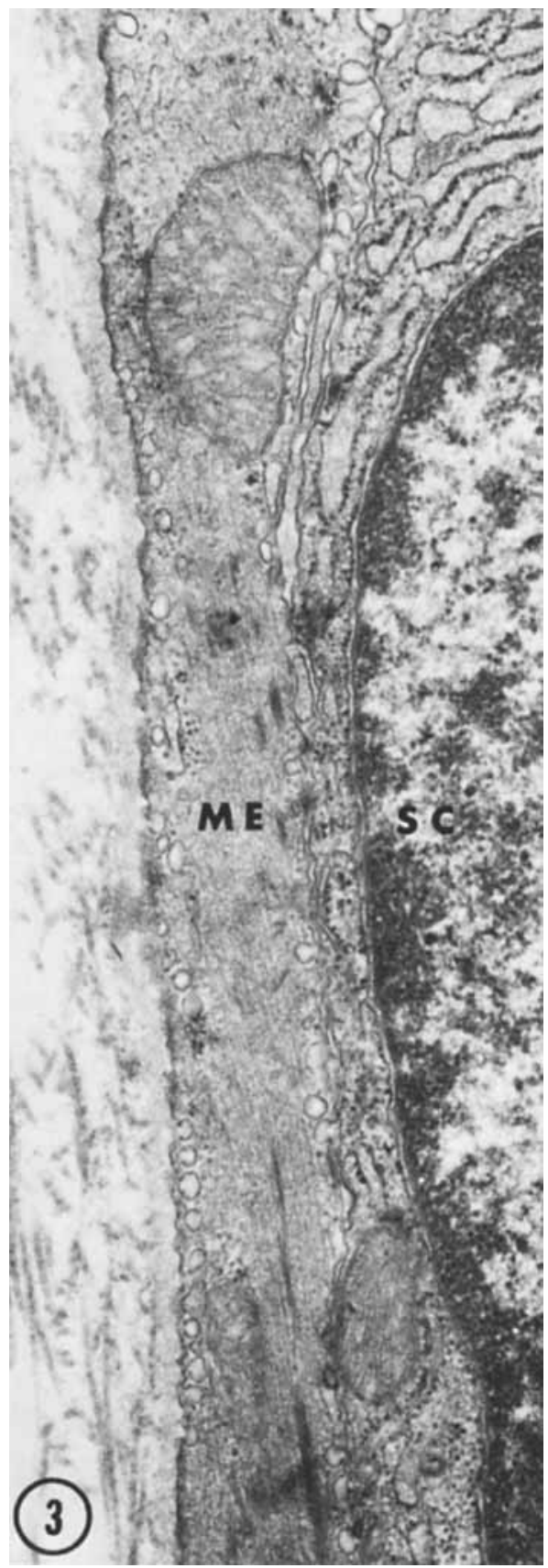

Fig. 3. A portion of a myoepithelial cell (ME). The cell is in close contact with a secretory cell (SC), a portion of which is shown on the right. The myoepithelial cell reveals thin fibrils and pinocytic vacuoles along the cell membrane. $(\times 36,800)$. 


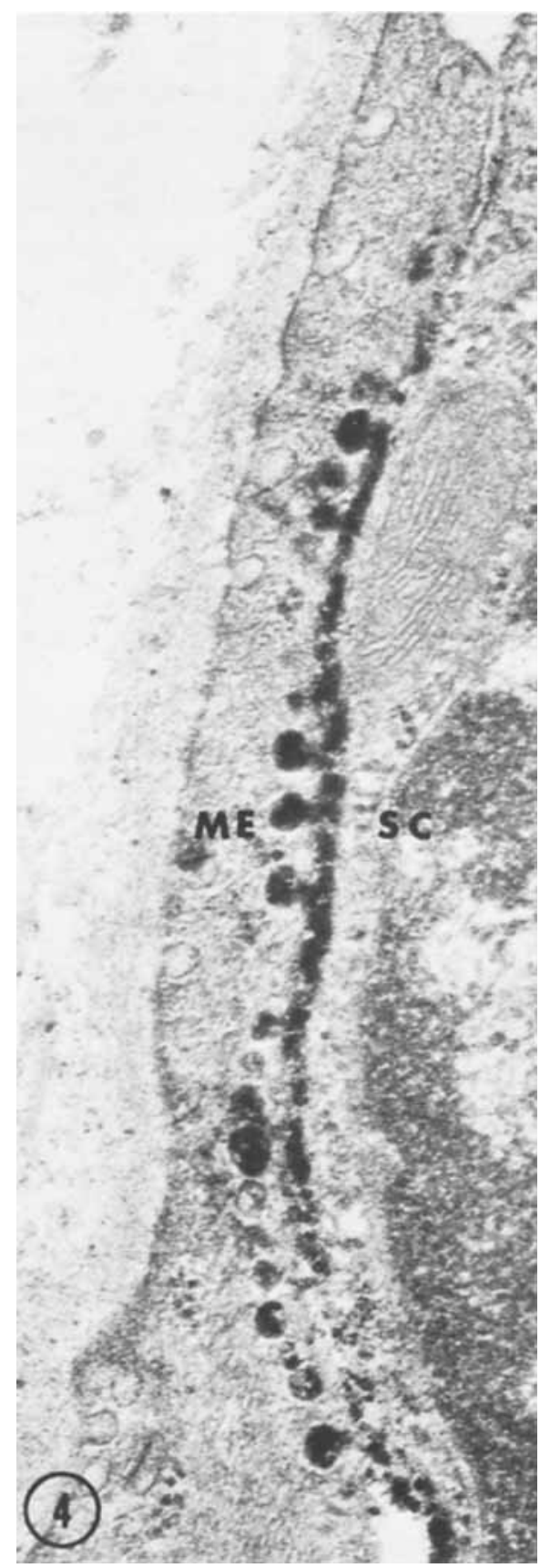

Fig. 4. A portion of a myoepithelial cell (ME) incubated for adenylate cyclase activity. The reaction product is localized in the intercellular space along the cell membrane near the secretory cell (SC) and pinocytic vesicles along this membrane. However, the reaction product is not present in vesicles along the basal membrane of the cell. $(\times 46,000)$. 
tended cell membrane which probably includes the membranes of many fused granules.

In the tissues incubated with ATP as substrate, the reaction product was found in the same two sites that showed a positive reaction with AMP-PNP as substrate. In addition, the reacton product was also found in association with the lateral and basal membranes of some cells.

The control tissues incubated without substrate did not reveal any reaction product. However, the tissues incubated in the complete medium without the activator revealed a small amount of reaction product which might be interpreted as the enzyme activity generated by the endogenous activators. The amount of reaction product detected appeared to be related to the concentration of isoproterenol added to the medium. The strongest reaction was observed with isoproterenol at a concentration of $10^{-4} \mathrm{M}$. But only a faint reaction could be noted with $10^{-5} \mathrm{M}$ and $10^{-3} \mathrm{M}$ concentrations of isoproterenol. The reaction product was not observed when the isoproterenol concentra. tion was raised to $10^{-2} \mathrm{M}$.

\section{DISCUSSION}

The bases of the cytochemical technique employed in this study are the precipitation of pyrophosphate or PNP liberated during conversion of ATP or AMP-PNP to cAMP by lead ions, and visualization of the complex in the electron microscope $(19,20)$. Several lines of evidence, although indirect, are in support of the specificity of the techniques for adenylate cyclase activity. (a) Results obtained previously from parallel biochemical and cytochemical studies have indicated that $10-50 \%$ of adenylate cyclase activity survived the fixation procedure. (b) There is a correlation between the amount of precipitate observed in the electron microscope and the enzyme activity determined biochemically (19). (c) It has been shown that AMP-PNP serves effectively as substrate for adenylate cyclase but it does not serve as a substrate for ATPase (21), and that AMP-PNP serves as substrate for adenylate cyclase in fixed and unfixed tissues (20). (d) The observations made in this study have demonstrated that the reaction product is not present in tissues incubated in the medium without the substrate. (e) In addition, the amount of deposit observed appears to depend on the concentration of the activator (isoproterenol) added. Therefore, it appears that the location of the reaction product coincides with the site of adenylate cyclase activity. The occurrence of the reaction product generated by the enzyme which survived the fixation and other cytochemical procedures employed indicates the presence of a high concentration or activity of the enzymes. However, the lack of reaction product cannot be interpreted necessarily as the absence of enzyme activities, since it could be due to the presence of a level of enzyme activity too low to be detected by cytochemical methods.

In the rat parotid and sublingual glands, then, a high level of adenylate cyclase activity seems to occur in association with the myoepithelial cell membranes in contact with both serous and mucous cells and with membranes forming secretory surfaces in serous secretory cells. The detection of the enzyme activity associated with the cell membrane is not surprising, as adenylate cyclase activity has been demonstrated previously in cell membranes of the rat parotid gland (10) and other tissues (9).

The localization of the reaction product in the intercellular space between myoepithelial cells and secretory acinar cells observed in this study suggests three possibilities. 

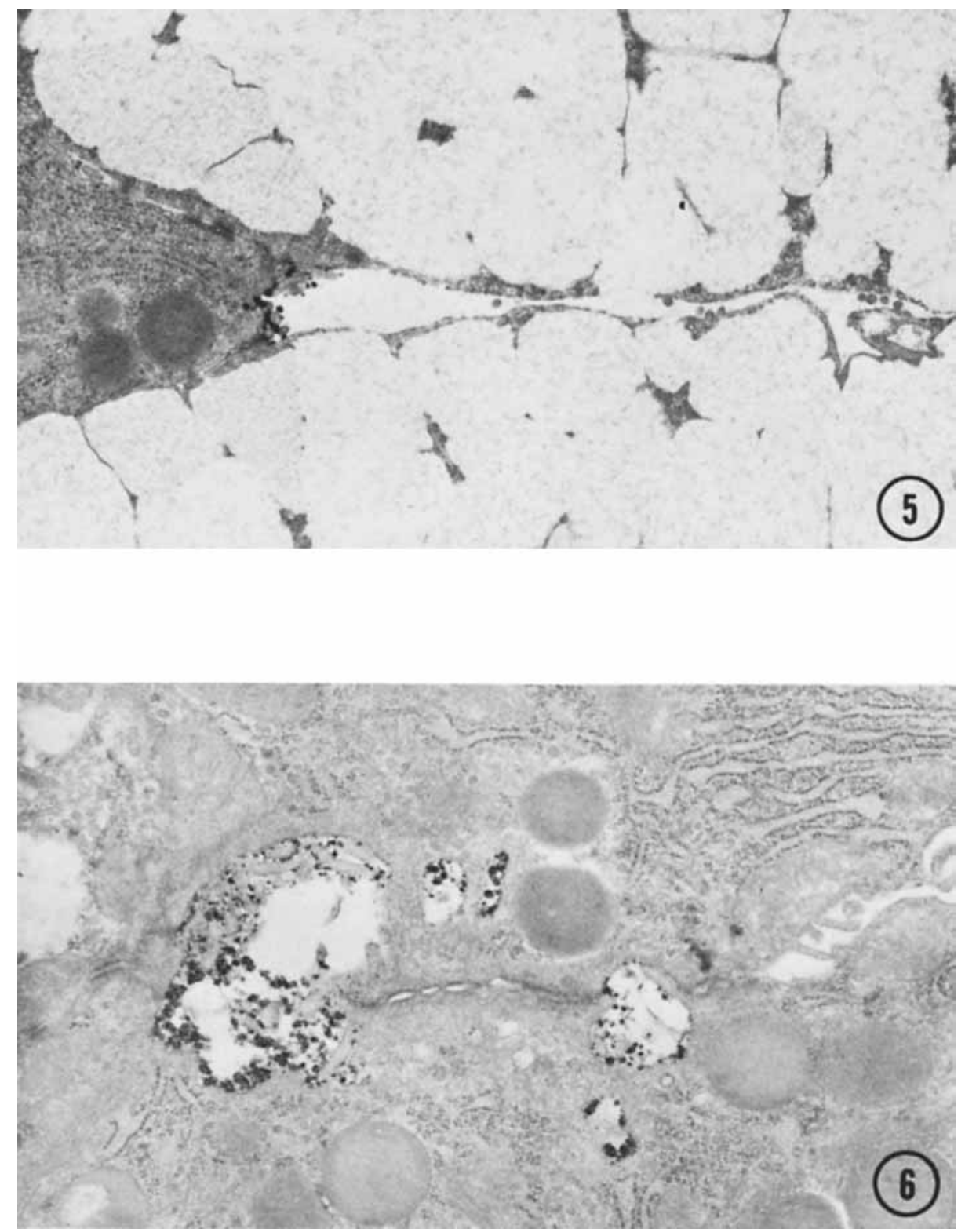

Figs. 5 and 6. A portion of the sublingual gland incubated for the demonstration of adenylate cyclase activity.

Fig. 5. The reaction product is localized along the luminal surface of the serous cell membrane but not along the same surface of the mucous cells. $(\times 20,000)$.

Fig. 6. The reaction product occurs along the membrane bordering the secretory lumens or may be canaliculi and small vescile-like structures near them. $(\times 25,000)$. 


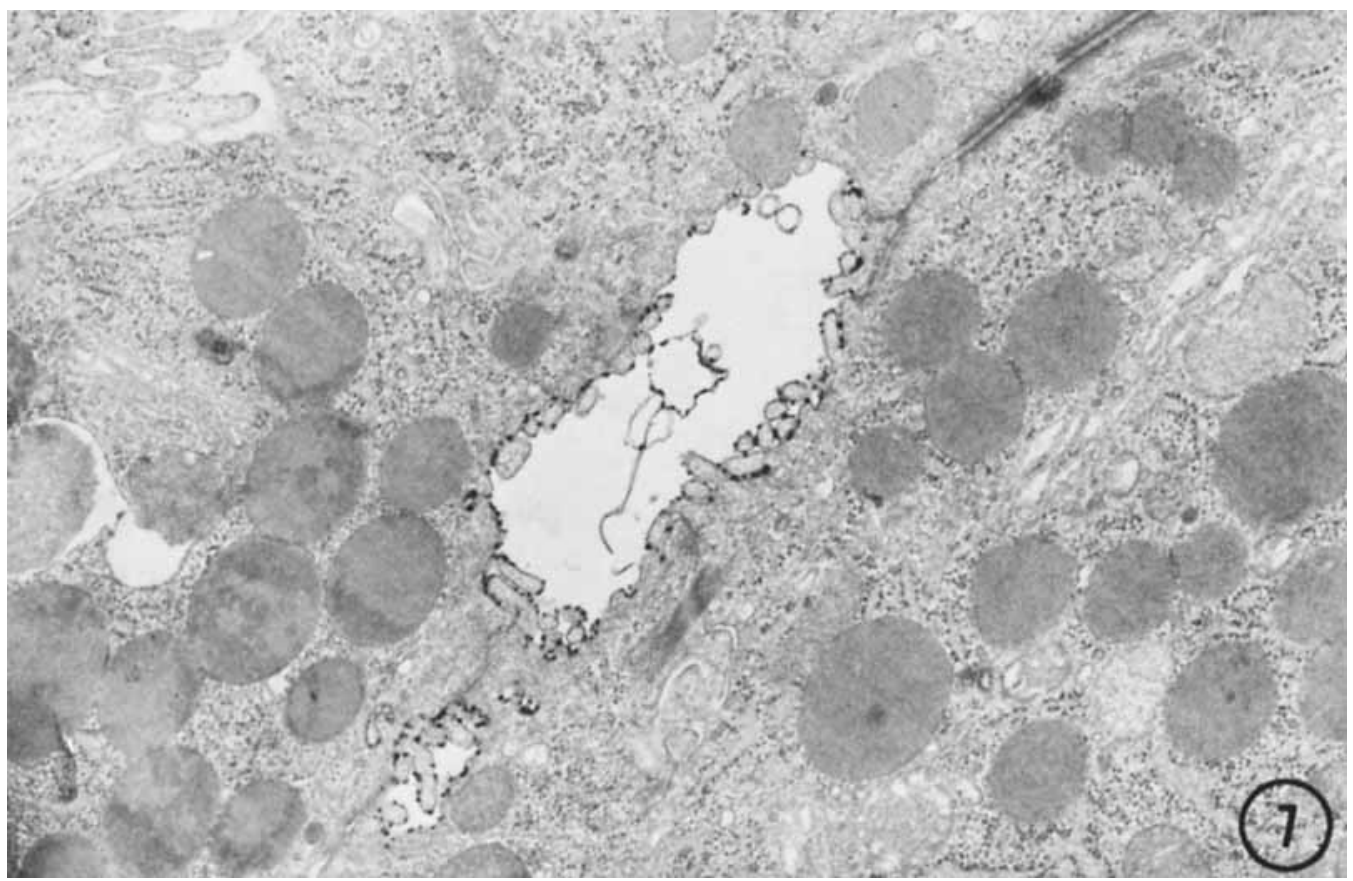

Figs. 7 and 8. A portion of the parotid gland incubated for the demonstration of adenylate cyclase activity.

Fig. 7. The reaction product occurs along the secretory surfaces (the membrane bordering the lumen $).(\times 20,000)$.

The first possibility is that adenylate cyclase is localized in the membrane of myoepithelial cells. The association of adenylate cyclase with the myoepithelial cell membranes is possible and this association can be related to the contractility of these cells. On the basis of the structural similarities between myoepithelial cells and smooth muscle cells and the close association between the former cells with secretory cells, it has been postulated that myoepithelial cells are contractile and that the contractility of these cells aids in expulsion of secretory materials from the secretory cells (24-26). The activation and inactivation of smooth muscle cell contractions appear to be mediated by a rise and fall, respectively, of $\mathrm{Ca}^{++}$in the cytoplasm (27--29). It is possible, then, that adenylate cyclase localized in myoepithelial cell membranes is concerned with the regulation of $\mathrm{Ca}^{++}$concentrations in this cell by modifying the permeability of cell membranes to $\mathrm{Ca}^{++}(7)$.

The second possibility is that adenylate cyclase is associated with the secretory cell membranes that are in contact with myoepithelial cells. Since cyclic AMP seems to be an intermediate in the salivary gland secretion (4-6), cyclic AMP catalyzed by adenylate cyclase localized in basal membranes of the secretory cells can facilitate the intracelluar events related to secretion. For example, mucous granules appear to fuse to each other prior to their discharge (18) and the processes of such fusion can be facilitated by the action of cAMP on mucous granule membranes. In serous cells, cAMP can facilitate 


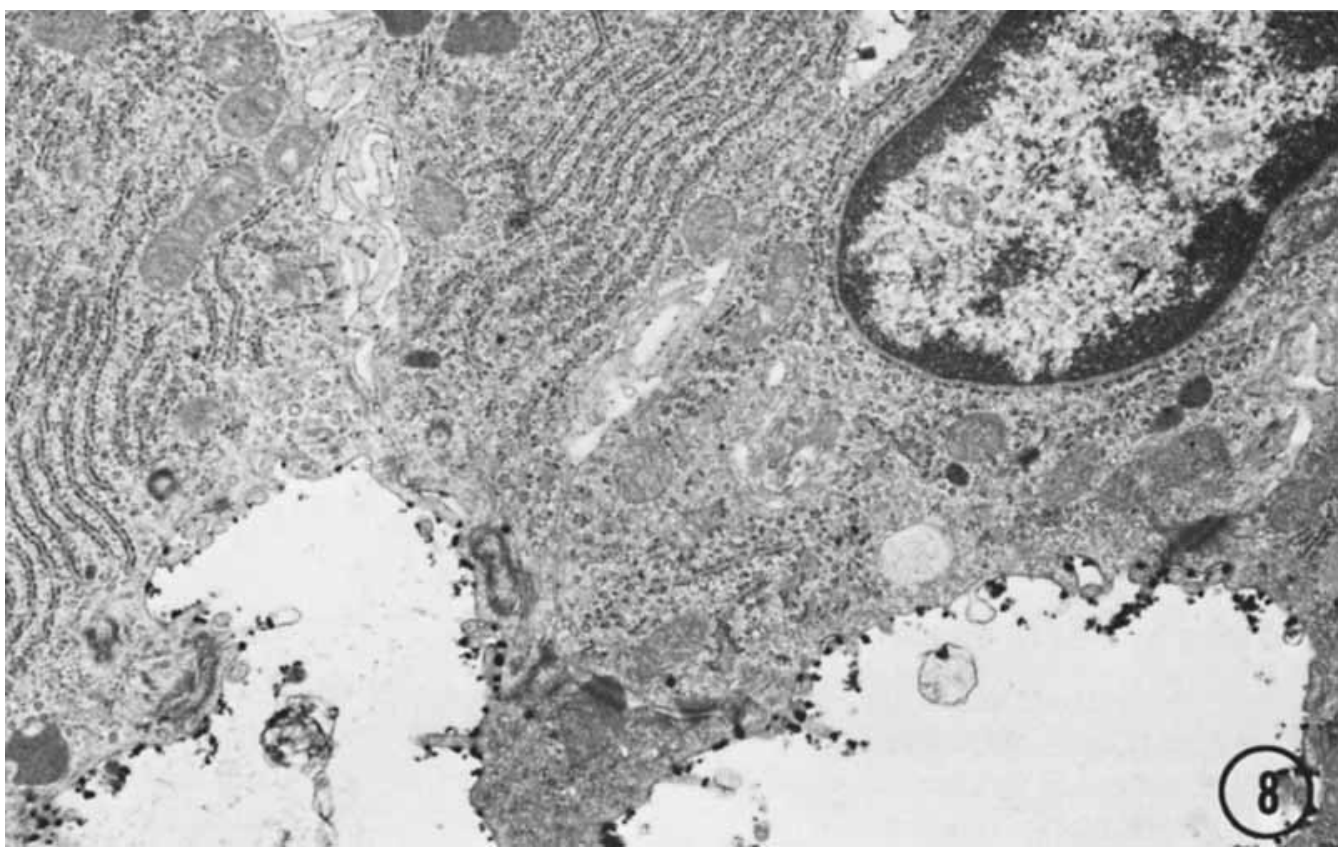

Fig. 8. The gland was obtained from a rat stimulated to secrete with isoproterenol and sacrificed $2 \mathrm{hr}$ after the stimulation. The cells are depleted of secretory granules. The reaction product occurs along the surface of the extended luminal membrane, parts of which are probably membranes of the granules fused with the cell membrane. $(\times 20,000)$.

the transport of secretory granules to the cytoplasm near the lumen, as $\mathrm{N}^{6}, \mathrm{O}^{2}$ '-dibutyryl cAMP seems to induce the granule discharge in parotid glands (6).

On the basis of the two possibilities discussed above, it is difficult to explain why the enzyme activity occurs polarized only in those portions of myoepithelial cells and secretory cells that are in contact with each other. For example, if adenylate cyclase of myoepithelial cells is related to the contractility of these cells, why is there no enzyme activity detectable in association with the basal membrane or vesicles near this membrane? Therefore, a logical alternative to the two possibilities mentioned above is the third possibility, that adenylate cyclase activity is distributed along the entire membrane of both cells, and that the activity is visualized only in the area where it is enhanced by a close contact of the two cell membranes. It is possible, since the absence of reaction product might indicate only the presence of a level of enzyme too low to be detected by cytochemical means and not the absence of the enzyme activity.

If this suggestion is correct, then the luminal membranes of the serous cells are associated with a much higher level of adenylate cyclase activity than are any other membranes, since these membranes always reveal clearly detectable amounts of deposits. This apparent high level of adenylate cyclase activity might be a property of the cell membrane forming the secretory surfaces and related to the role this membrane plays in secretory function. This is the portion of the cell membrane that fuses with the 
granule membrane during secretion, and the high level of adenylate cyclase activity might be related to the ability of this membrane to fuse with other membranes. Interestingly, the luminal membrane of mucous cells does not fuse with the membranes of mucous granules during secretion and this membrane is apparently not associated with any detectable enzyme activity. Furthermore, Amsterdam et al. (12) have observed that a granule membrane fuses with additional granules only after it becomes part of the luminal membrane. On the basis of this observation, they suggested the possible involvement of cyclic AMP in the process of the transition of one type of membrane to another. Since cyclic AMP seems to play a role in biochemical events related to membrane modification $(2,7)$, the finding in this study of the high level of adenylate cyclase activity associated with the luminal membrane of serous cells is not at all surprising. Since adenylate cyclase activity is not detected in secretory granules (10), either the granule membranes acquire the enzyme activity following the fusion with the cell membrane, or the enzyme activity inhibited in the granules becomes activated by the abolition of the inhibitor.

\section{NOTE ADDED IN PROOF}

Recently an article appeared which showed lead inhibition of adenylate cyclase activity (Lemay, A., and Jarett, L., J. Cell Biol. 65:39, 1975). The authors' conclusions are based on the biochemical study of fresh, isolated cells from fat pad capillaries and pancreatic islet homogenates. In the fixed tissues examined in the present study, the localization of the reaction product is restricted, and its amount appears to depend upon the concentration of the activator. Therefore, the effect of lead on adenylate cyclase activity in fixed and unfixed cells from different tissues requires further examination.

\section{ACKNOWLEDGMENTS}

This is Veterans Administration Research Project no. 4927:01. The author gratefully acknowledges the technical assistance and effort in the preparation of this manuscript provided by Virginia Hartog.

\section{REFERENCES}

1. Jost, J. -P., and Rickenberg, H. V., Annu. Rev. Biochem. 40:741 (1971).

2. Robison, G. A., Butcher, R. W., and Sutherland, E. W., Annu. Rev. Biochem. 37:149 (1968).

3. Sutherland, E. W., Robison, G. A., and Butcher, R. W., Circulation 37:279 (1968).

4. Bdolah, A., and Schramm, M., Biochem. Biophys. Res. Commun. 18:452 (1965).

5. Babad, H., Ben-Zvi, R., Bdolah, A., and Schramm, M., Eur. J. Biochem. 1:96 (1967).

6. Butcher, F. R., and Goldman, R. H., J. Cell Biol. 60:519 (1974).

7. Rasmussen, H., and Tenenhouse, A., Proc. Natl. Acad. Sci. 59:1346 (1968).

8. Sutherland, E. W., Rall, T. W., and Menon, T., J. Biol. Chem. 237:1220 (1962).

9. Davoren, P. R., and Sutherland, E. W., J. Biol. Chem. 238:3016 (1963).

10. Schramm, M., and Naim, E., J. Biol. Chem. 12:3225 (1970).

11. Ichikawa, A., J. Cell Biol. 24:369 (1965).

12. Amsterdam, A., Ohad, I., and Schramm, M., J. Cell Biol. 41:753 (1969).

13. Hand, A. W., J. Cell Biol. 44:340 (1970).

14. Hollman, K. H., Ann. N.Y. Acad. Sci. 106:545 (1963).

15. Freeman, J. A., Anat. Rec. 154:121 (1966).

16. Neutra, M., and Leblond, C. P., J. Cell Biol. 30:119 (1966). 
17. Tandler, B., Denning, C. R., Mandel, I. D., and Kutscher, A. H., J. Morphol. 130:227 (1970).

18. Kim, S. K., Nasjleti, C. E., and Han, S. S., J. Ultrastruct. Res. 38:371 (1972).

19. Reik, L., Petzold, G. L., Higgins, J. A., Greengard, P., and Barrnett, R. J., Science 168:382 (1970).

20. Howell, S. L., and Whitfield, M., J. Histochem. Cytochem. 20:873 (1972).

21. Rodbell, M., Birnbaumer, L., Pohl, S. L., and Krans, H. M. J., J. Biol. Chem. 246:1877 (1971).

22. Yount, R. G., Babcock, D., Ballantyne, W., and Ojala, D., Biochemistry 10:2484 (1971).

23. Maguire, M. E., and Gilman, A. G., Biochim, Biophys. Acta 358:154 (1974).

24. Tamarin, A., J. Ultrastruct. Res. 16:320 (1966).

25. Tandler, B., Denning, C. R., Mandel, I. D., and Kutscher, A. H., J. Morphol. 130:227 (1970).

26. Tandler, B., in "Proceedings of Symposium on Salivary Glands and Their Secretion,"

N.H. Rowe (Ed.). The University of Michigan, Ann Arbor, Mich., p. 8 (1972).

27. Hurwitz, L., and Suria, A., Annu. Rev. Pharmacol. 11:303 (1971).

28. Somlyo, A. P., and Somlyo, A. V., Pharmacol. Rev. 20:197 (1968).

29. Somlyo, A. P., and Somlyo, A. V., Pharmacol. Rev. 22:249 (1970). 